\title{
Mechanical Characterization of Anion Exchange Membranes by Extensional Rheology under Controlled Hydration
}

\author{
Melissa A. Vandiver, ${ }^{\text {a,* }}$ Benjamin R. Caire, ${ }^{\text {a,* }}$ Jordan R. Carver, ${ }^{\text {a }}$ Krysta Waldrop, ${ }^{\text {a }}$ \\ Michael R. Hibbs, ${ }^{\mathrm{b}}$ John R. Varcoe, ${ }^{\mathrm{c}, * *}$ Andrew M. Herring, ${ }^{\mathrm{a}, * *}$ and Matthew W. Liberatore ${ }^{\mathrm{a}, \mathrm{z}}$ \\ ${ }^{a}$ Department of Chemical and Biological Engineering, Colorado School of Mines, Golden, Colorado 80401, USA \\ ${ }^{b}$ Materials, Devices, \& Energy Technologies Group, Sandia National Laboratory, Albuquerque, \\ New Mexico 87185, USA \\ ${ }^{c}$ Department of Chemistry, Faculty of Engineering and Physical Sciences, The University of Surrey, \\ Guildford GU2 7XH, United Kingdom
}

\begin{abstract}
Alkali anion exchange membrane (AEM) based devices have the potential for electrochemical energy conversion using inexpensive catalysts and a variety of fuel types. Membrane stability and anion transport must be improved in AEMs before these devices can be fully realized. Mechanical failure of the membrane can contribute to failure of the device, thus membrane durability is critical to overall system design. Here, a study of the mechanical properties of three well-established AEMs uses a modified extensional rheometer platform to simulate tensile testing using small membrane samples. Mechanical properties were tested at 30 and $60^{\circ} \mathrm{C}$ under dry or water saturated gas conditions. Water in the membrane has a plasticizing effect, softening the membrane and reducing strength. PEEK membrane reinforcement limits swelling producing negligible softening and only a $9 \%$ decrease in strength from dry to hydrated conditions at $30^{\circ} \mathrm{C}$. Higher cation concentration increases water uptake resulting in significant softening, a $57 \%$ reduction in Young's modulus, and a $67 \%$ reduction in strength when hydrated at $30^{\circ} \mathrm{C}$. In a working electrochemical device, AEMs must maintain integrity over a range of temperatures and hydrations, making it critical to considering mechanical properties when designing new membranes.

(C) The Author(s) 2014. Published by ECS. This is an open access article distributed under the terms of the Creative Commons Attribution 4.0 License (CC BY, http://creativecommons.org/licenses/by/4.0/), which permits unrestricted reuse of the work in any medium, provided the original work is properly cited. [DOI: 10.1149/2.0971410jes] All rights reserved.
\end{abstract}

Manuscript submitted June 16, 2014; revised manuscript received July 18, 2014. Published July 26, 2014. This was Paper 1570 presented at the San Francisco, California, Meeting of the Society, October 27-November 1, 2013.

Polymer electrolyte membrane fuel cells and electrolyzers are potentially disruptive technologies that will replace traditional heat engines such as internal combustion engines for transportation applications, portable electronics, and are scalable to larger energy storage facilities. Polymer electrolyte membrane fuel cells are suitable for transportation applications due to their low temperature start-up and operation, high power density, and quick refueling. ${ }^{1-3}$ Proton exchange membranes (PEMs) have dominated polymer electrolyte membrane fuel cell development in the last several decades, resulting in the development of relatively stable, well performing membranes. ${ }^{1-4}$ Current PEM fuel cells remain cost prohibitive due to high catalysts costs, as well as long-term durability issues. ${ }^{3,5,6}$ Anion exchange membranes (AEMs) can also be utilized in polymer electrolyte membrane devices and have several potential benefits over PEMs. AEM fuel cells benefit from increased kinetics in an alkali media allowing more complex fuels then hydrogen and have the potential to utilize non-platinum catalysts to reduce costs. ${ }^{7-11}$ However, a number of challenges must be overcome before AEMs reach the performance and durability necessary for fuel cells and other electrochemical energy conversion devices. Hydroxide present in the AEM degrades many of the proposed cationic groups and some polymer backbones, making development of chemically stable AEMs difficult. ${ }^{9,11,12}$ Additionally, transport of hydroxide in AEMs is inherently slower than protons in PEMs, ${ }^{13}$ to compensate, the concentration of ionic groups is often increased in AEMs. ${ }^{8}$ Increasing ion concentration in AEMs increases water sorption in the polymer and can result in significant dimensional swelling, which can alter the mechanical integrity of the membrane. Thus, simultaneous studies of ionic transport, water sorption, and mechanical durability are necessary to develop an optimized AEM. Research efforts primarily focus on improving ionic transport and water sorption, while mechanical stability of AEMs is often a secondary consideration. The lower transport efficiency of AEMs makes thin membranes critical to minimize area specific resistance, however, maintaining mechanical integrity of thin membranes is difficult. ${ }^{10}$ Considering mechanical properties of new AEMs and

\footnotetext{
*Electrochemical Society Student Member.

**Electrochemical Society Active Member.

zE-mail: mliberat@mines.edu
}

tailoring membrane design toward robust, thin films is critical for the realization of AEM energy conversion devices in the future.

Fuel cell lifetime is often determined by the ability of the membrane to resist mechanical degradation..$^{3,6,14-16}$ Mechanical degradation of the membrane occurs through a combination of physical and chemical stresses present in the fuel cell. ${ }^{17} \mathrm{~A}$ working fuel cell has a dynamic temperature and humidity environment resulting in changes in membrane hydration. Sorption and desorption of water can produce significant swelling and hygrothermal stresses in the membrane. ${ }^{3,6,17}$ As the membrane is constrained in the membrane electrode assembly (MEA), dimensional swelling of the membrane results in stresses on the assembly and membrane. The hygrothermal stresses experienced by the membrane due to swelling and contraction can lead to pinhole and crack formation. ${ }^{15}$ These defects weaken the membrane, leading to mechanical failure, and allowing crossover in electrochemical energy conversion devices. Crossover results in radical formation that can further degrade the membrane chemically. ${ }^{17}$ Decoupling the effects of chemical and mechanical degradation is difficult in in-situ fuel cell tests, particularly over the short time-span of traditional testing, making it critical to develop ex-situ, accelerated test methods to gauge mechanical degradation. Thorough studies have been performed on the mechanical strength, durability, and failure mechanisms of PEMs, ${ }^{3,6,18}$ and this information can be used to guide AEM development and testing. Ex-situ durability tests to gauge membrane lifetime of PEMs include rapid humidity cycling while monitoring gas crossover, ${ }^{19}$ pressurized blister tests,${ }^{20}$ and mechanical fatigue testing by dynamic mechanical analysis. ${ }^{14}$ These tests have been shown to accurately predict relative membrane lifetimes. Traditional tensile tests are a less accurate predictor of membrane lifetime in a fuel cell, but remain the standard characterization for comparing mechanical properties of polymer films. ${ }^{3}$ Additionally, measurement of tensile properties at a range of temperature and humidity conditions is an important screening tool to gauge membrane potential as membranes become brittle and fragile at low hydrations. ${ }^{6}$

Increasing durability of the polymer membrane is necessary for application in fuel cells, ${ }^{5,10,11}$ particularly in AEMs where thinner films are needed. A number of design factors can influence membrane strength and durability. Polymer chemistry is responsible for the basic mechanical properties of the membrane. ${ }^{9}$ Block copolymer 
AEMs offer the opportunity to tailor mechanical properties by selecting the polymer chemistry of the hydrophobic block to tune desired properties. Since a chemically stable AEM with sufficient durability is not commercially available, many polymer chemistries are under investigation, and screening these polymers for mechanical properties will lead to the development of durable membranes. PEM research has shown that a higher degree of crystallinity can improve mechanical properties. ${ }^{4}$ Increasing polymer crystallinity can be achieved by altering polymer chemistry, such as reducing the side chain length in perfluorosulfonic acid (PFSA) PEMs ${ }^{21}$ or through various annealing techniques. Crosslinking is another common technique to improve membrane strength. ${ }^{4,22}$ Chemically crosslinking polymer chains increases the modulus and strength, however the method of crosslinking may reduce the ionic concentration and a high degree of crosslinking may cause membrane embrittlement. Physical reinforcement of membranes with a nonconductive, porous polymer film can also significantly improve durability, as long as it is also chemically stable to hydroxide. ${ }^{23}$ Porous polytetrafluoroethylene (PTFE) membranes and fibers have been incorporated into PFSAs to improve mechanical durability. ${ }^{3,4,24}$ Reinforcing an ion exchange membrane also helps resist dimensional swelling, increasing stability between dry and hydrated states and prolonging membrane lifetime. ${ }^{6,16}$ While physical reinforcement can strengthen the membrane and resist changes with hydration, the addition of a nonconductive material lowers the ion exchange capacity of the membrane. While a number of design factors can impact the mechanical durability of an AEM, consideration of these factors early in AEM research is important to develop satisfactory fuel cell membranes.

The mechanical behaviors of Nafion and similar PFSAs have been studied in detail at a wide range of temperature and humidity conditions. $^{3,18,25}$ However, because AEM development is still preliminary, basic mechanical testing is not standardized and comparing mechanical properties of AEMs is difficult. In this study, the extensional properties of three well-studied AEMs were investigated under different temperature and humidity conditions. The AEMs used in this study are the industrially produced polyetheretherketone (PEEK) reinforced Fumasep FAA-PEEK membrane from Fumatech, ${ }^{26}$ an aminated tetramethyl polyphenylene (ATMPP) developed at Sandia National Laboratory, ${ }^{27-29}$ and a radiation grafted poly(ethylene-cotetrafluoroethylene)-based quaternary ammonium AEM developed at the University of Surrey. ${ }^{30,31}$ The three membranes were chosen as they have all been produced consistently in multi-gram quantities, the first under industrial quality control standards, the second in large research batches over multiple years, and the third from an industrially produced precursor film. This study compares the mechanical properties of these AEMs at a range of temperature and humidity conditions using a modified extensional rheometer system to simulate traditional tensile tests, and relates these properties to water uptake and swelling of the membranes.

\section{Experimental}

Materials.-Three AEM membranes were tested: Fumasep FAA-PEEK (Fumatech), an aminated tetramethyl polyphenylene (ATMPP) with benzyltrimethylammonium functionalities, and a poly(ethylene-co-tetrafluoroethylene) membrane radiation grafted with poly(vinylbenzyl trimethylammonium) groups (ETFEg-PVBTMA) (Figure 1). The Fumasep FAA-PEEK membrane is a PEEK reinforced anion exchange membrane with a dry thickness of $110 \mu \mathrm{m}$ and an IEC of $1.5 \mathrm{mmol} / \mathrm{g}$. The chemistry of Fumasep FAA-PEEK was not disclosed, but literature has suggested a polysulfone or perfluorinated backbone with quaternary ammonium functionalities. ${ }^{32,33}$ The Fumasep membrane was in a dry state in the $\mathrm{Cl}^{-}$form and was tested as received. The ATMPP membrane was fabricated as previously reported by Hibbs..$^{27,28}$ The ATMPP membrane had a dry thickness of $80 \mu \mathrm{m}$ and an IEC of $2.5 \mathrm{mmol} / \mathrm{g}$. The ATMPP membrane was received in the $\mathrm{Br}^{-}$form and stored in liquid water. The ATMPP membrane was dried at ambient conditions prior to mechanical testing. Membranes were tested in their as-received counter-ion form to be comparable to literature, however additional mechanical testing of the ATMPP in the $\mathrm{Cl}^{-}$form was performed for consistency and to guarantee counter-ion association did not significantly change mechanical properties. The ETFE-g-PVBTMA membrane was fabricated as previous described by the University of Surrey group. ${ }^{30,31}$ The ETFE-g-PVBTMA had a dry thickness of $80 \mu \mathrm{m}$ and an IEC of $1.8 \mathrm{mmol} / \mathrm{g}$. The membrane was received in a dry state in the $\mathrm{Cl}^{-}$ form and tested without further treatment.

Water uptake.- Water uptake and saturation equilibration times were determined using a dynamic vapor sorption apparatus (SMS DVS Advantage 1). The mass of a membrane sample, about $4 \mathrm{~mm}^{2}$, was measured gravimetrically under different humidity conditions. The water uptake (WU) of the membrane was calculated based on Equation 1.

$$
\mathrm{WU}=\frac{m_{\% R H}-m_{d r y}}{m_{d r y}} \times 100
$$
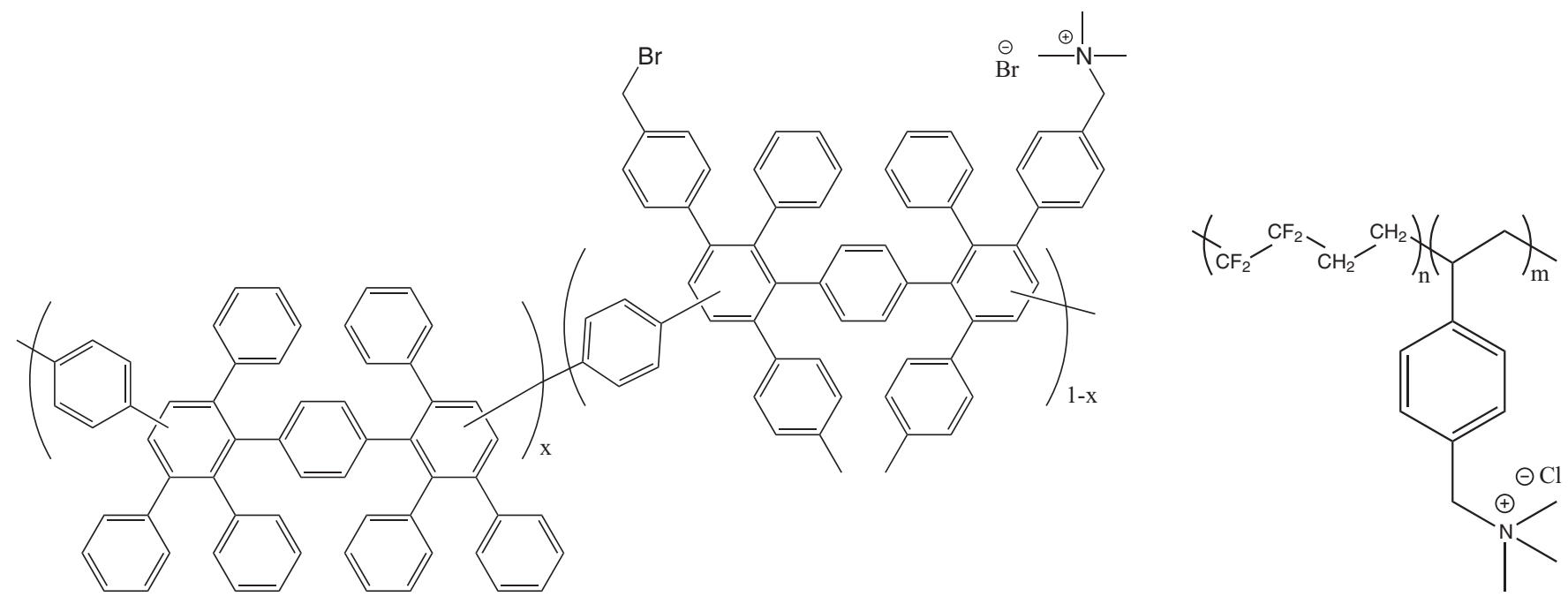

(a)

(b)

Figure 1. Chemical structures of the a) ATMPP and b) ETFE-g-PVBTMA polymers. 
Where $m_{\% R H}$ is the mass of the sample at the given relative humidity and $m_{d r y}$ is the mass of the dry sample. The mass of the dry membrane was taken as the measured mass at the end of an initial three-hour drying period. Given the water uptake at saturated conditions and the known ion exchange capacity of the membrane, the hydration level, $\lambda$, which is the number of waters per cation functional group, can be calculated using Equation 2

$$
\lambda=\frac{\mathrm{WU}}{m\left(\mathrm{H}_{2} \mathrm{O}\right) \cdot \mathrm{IEC}}
$$

where $m\left(\mathrm{H}_{2} \mathrm{O}\right)$ is the molar mass of water.

Dimensional swelling. - Dimensional swelling of the AEM films with water was calculated by measuring film area and thickness dried at ambient conditions compared to films soaked in water at room temperature for two days. In-plane length and width measurements were made using a Marathon electronic digital caliper $(0-150 \mathrm{~mm}$, with $0.01 \mathrm{~mm}$ accuracy) and through-plane thickness measurements were made using a Marathon electronic digital micrometer (0-25 $\mathrm{mm}$, with $0.002 \mathrm{~mm}$ accuracy). Wet membranes were removed from water and blotted to remove surface water; measurements were made as quickly as possible to prevent drying. Swelling was calculated with respect to the percent change of in-plane area and through-plane thickness of the film.

Conductivity. - Ionic conductivity was calculated by measuring membrane resistance with electrochemical impedance spectroscopy. Impedance spectra were obtained over a frequency range of 1 to $10^{6} \mathrm{~Hz}$ using a four-electrode test cell and multi-channel potentiostat (BioLogic VMP3, Knoxville, TN). The membrane resistance was defined as the low frequency intercept of the Nyquist impedance plot and used to calculate conductivity based on Equation 3

$$
\sigma=\frac{l}{R \cdot t \cdot w}
$$

where $R$ is membrane resistance, $l$ is the length between electrodes, and $t$ and $w$ are the membrane thickness and width respectively. The test cells were kept in a controlled environment (TestEquity Model $1007 \mathrm{H}$, Moorpark, CA) to maintain relative humidity and temperature.

Tensile tests. - Mechanical tests were performed using a Sentmanat Extensional Rheometer (SER) fixture ${ }^{34}$ (Xpansion Instruments) on an ARES G2 rheometer platform (TA Instruments). The SER fixture suspends the membrane across two counter rotating drums. The rheometer controls the rotation of the drums, which stretch the sample to failure. The stress on the membrane sample is measured by the rheometer during film extension. The SER fixture is generally used to measure the elongation viscosity of polymers in their melt state, but has been shown to accurately measure tensile properties in the solid state. ${ }^{34}$ The stress vs. strain data is used to determine the elastic modulus, ultimate strength, and elongation of the film. The modulus is defined as the slope of the stress vs. strain curve in the initial liner region that corresponds to elastic deformation. The engineering stress at break is defined as the stress measured immediately prior to break, based on the initial film dimensions. The elongation of the membrane is the percent increase in film length as determined by the strain at break.

Polymer films were cut into strips of $25 \mathrm{~mm}(\mathrm{~L}) \times 3 \mathrm{~mm}(\mathrm{~W})$, about $5-10 \mathrm{mg}$, for testing. The SER drums were wrapped in double-sided high temperature tape to prevent slipping of the films. Silicon coated screw-down pins secured the film to the drum surface; additionally tape was place over the outer edges of the film, outside the sample area. The Hencky strain rate at which the films were stretched was based on the ultimate elongation: $0.0033 \mathrm{~s}^{-1}(0.021 \mathrm{~mm} / \mathrm{s})$ for elongations less than $20 \%, 0.0167 \mathrm{~s}^{-1}(0.106 \mathrm{~mm} / \mathrm{s})$ for elongations between 20 and $100 \%$, and $0.33 \mathrm{~s}^{-1}(2.12 \mathrm{~mm} / \mathrm{s})$ for elongations greater than $100 \%$. These strain rates were calculated based on ASTM D882-12 for tensile testing of thin plastic sheeting, but modified to account for the predefined sample distance between the drums. Samples were tested under dry airflow at $30^{\circ} \mathrm{C}$ and $60^{\circ} \mathrm{C}$. Dry test conditions were achieved using the forced convection oven (FCO) built into the ARES rheometer. Samples were allowed to equilibrate at temperature for $10 \mathrm{~min}$ before the tensile tests. Samples were also tested under saturated gas conditions at $30^{\circ} \mathrm{C}$ and $60^{\circ} \mathrm{C}$. Humidified gas was supplied by a combination of dry and wet gas flows controlled by to two mass flow controllers $\left(10,000 \mathrm{~cm}^{3} / \mathrm{min}\right.$ capacity, MKS $\left.1179 \mathrm{~A}\right)$. The wet gas was passed through a humidity bottle (FCT, Inc.) with $10 \mathrm{~m}$ of Nafion tubing to saturate the air with water. The wet and dry gas flows were combined and delivered to the ARES sample chamber through heated lines, to prevent condensation in the tubing. A humidity probe (Vaisala HMT 337) measures the dew point in the sample chamber and provides real time humidity conditions. Humidified samples were allowed to equilibrate (and take up water) for $40 \mathrm{~min}$, except the ATMPP membrane that equilibrated for $1 \mathrm{~h}$. These equilibration times were determined by separate dynamic vapor sorption experiments (described earlier), during which the gravimetric change in mass of polymer is measured with respect to humidity.

\section{Results and Discussion}

The charged nature of an AEM causes sorption of water into the polymer from surrounding vapor or liquid. Water uptake has a significant impact on ion transport, mechanical properties, and membrane performance. Water is critical to maintain ionic conductivity to facilitate ion diffusion and allow for Grotthuss charge hopping. ${ }^{10}$ Sorption of water into the polymer can have a plasticizing effect on the membrane, which is quantified by increases in elasticity and elongation as well as a reduction in membrane strength. ${ }^{18,25}$ Generally, water uptake is proportional to IEC, and the water uptake can be translated to the number of water molecules associated with each cationic group. Accurately measuring water uptake at different relative humidities is critical to understanding how mechanical properties change under different environmental conditions.

Water uptake was measured for each AEM at $30^{\circ} \mathrm{C}$ and $60^{\circ} \mathrm{C}$ to determine the time required to reach full saturation in the film and relate changes in mechanical properties to relative humidity, Figure 2. The FAA-PEEK membrane has the lowest water uptake of the AEMs, $4.8 \%$ and $7.2 \%$ at $30^{\circ} \mathrm{C}$ and $60^{\circ} \mathrm{C}$ respectively, corresponding to lambda equal to 1.8 and 2.7 respectively. The low water uptake of the FAA-PEEK membrane is a result of its low IEC and PEEK reinforcement that restricts dimensionally swelling. Due to its high IEC, the ATMPP membrane had the highest water uptake of $14 \%$ (lambda of 3.1) at both temperatures tested. This water uptake is lower than literature values for liquid water uptake $(64-72 \%)^{28}$ and gas phase water uptake with $1 \mathrm{hr}$ humidity steps (27\%) but similar to the gas phase water uptake with 20 min humditiy steps $(17 \%){ }^{29}$ The ETFE-g-PVBTMA had moderate water uptake of $6.2 \%$ at $30^{\circ} \mathrm{C}$ and $10.4 \%$ at $60^{\circ} \mathrm{C}$, corresponding to lambda equal to 1.9 and 3.2 respectively. These water uptakes are lower than literature values for uptake from liquid water $(40 \%) .{ }^{30}$ The level of water uptake and hydration number will be related to the mechanical behavior of hydrated films described below.

Dimensional swelling was measured with respect to the in-plane area and through-plane thickness of the film (Figure 3). As expected, the FAA-PEEK membrane showed the lowest swelling due to its low water uptake and PEEK reinforcement. The FAA-PEEK membrane is the only AEM to have a larger through-plane swelling, 9\%, compared to in-plane swelling, 3\%, due to the PEEK reinforcement preventing swelling in the in-plane direction. The ATMPP and ETFEg-PVBTMA films show a similar amount of swelling, with in-plane swelling being higher, 26-27\%, compared to 14-19\% in the throughplane direction. Dimensional swelling can be problematic in AEM based devices because the membrane is constrained by bipolar plates, and excessive dimensional changes could lead to delamination of the catalyst layers as well as mechanical failure of the membrane. Membrane elasticity must be adequate to allow swelling and deswelling without developing cracks or holes in the membrane. Maintaining 

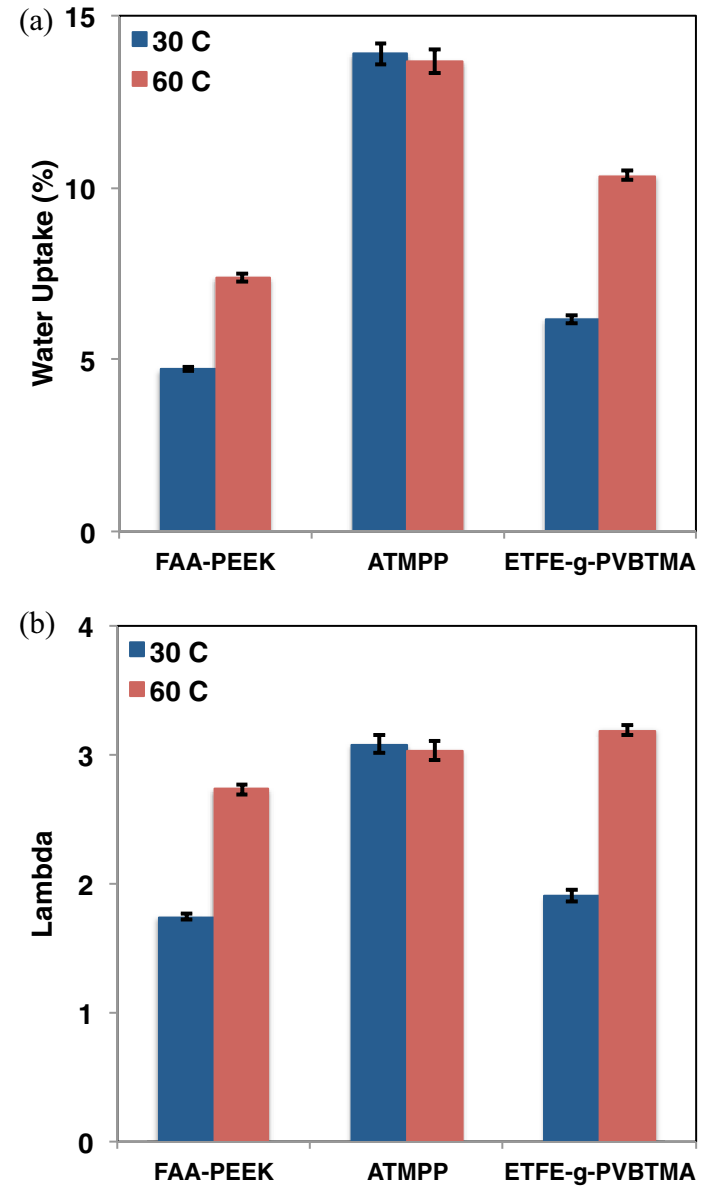

Figure 2. Comparison of water uptake and lambda for the membranes at $30^{\circ} \mathrm{C}$ and $60^{\circ} \mathrm{C}$ under saturated gas conditions.

adequate hydration and ion conduction while limiting dimensional swelling will improve the lifetime of an AEM based devices.

The ionic conductivity of the AEMs was measured to establish the relationship between ion conduction with IEC and water uptake. Conductivity in the halide form, chloride for FAA-PEEK and ETFE-gPVBTMA and bromide for ATMPP, was measured for all membranes at saturated relative humidity and $60^{\circ} \mathrm{C}$. The FAA-PEEK film had

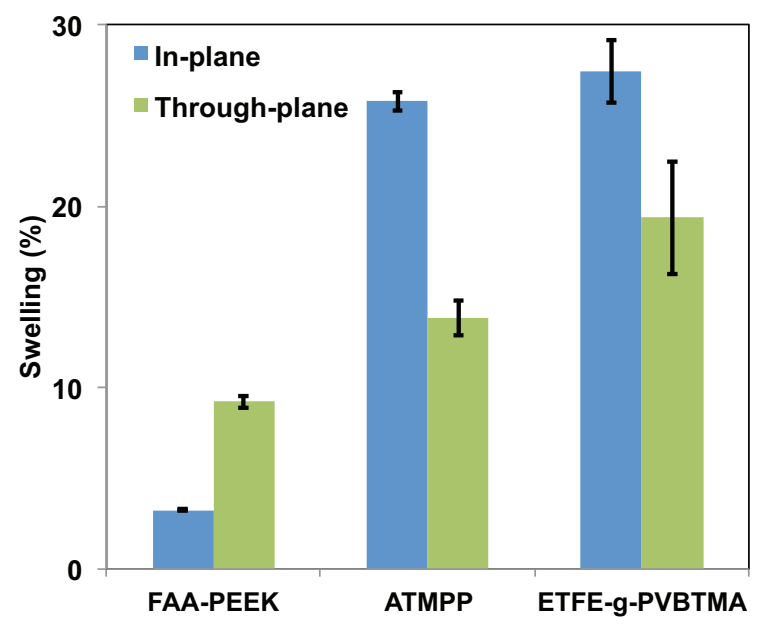

Figure 3. Dimensional swelling of AEM films soaked in liquid water compared to dry films at ambient conditions. the lowest conductivity of $11.6 \pm 0.8 \mathrm{mS} / \mathrm{cm}$ as a result of its low IEC and relatively low water uptake compared to the other films. The ATMPP film, which had the highest IEC and water uptake of all films tested, had a conductivity of $20 \pm 2 \mathrm{mS} / \mathrm{cm}$. This value is similar to ATMPP bromide conductivities reported in literature, 10$38 \mathrm{mS} / \mathrm{cm} .{ }^{28,29}$ The ETFE-g-PVBTMA had the highest conductivity of $47 \pm 3 \mathrm{mS} / \mathrm{cm}$, which is higher than through-plane carbonate or bicarbonate conductivities reported in literature $(17-25 \mathrm{mS} / \mathrm{cm}) .{ }^{30,31}$ Ion transport is significantly influenced by IEC and water sorption in the membrane and these factors will also have a large impact on mechanical performance.

At the lower temperature $\left(30^{\circ} \mathrm{C}\right)$ and dry conditions all AEMs tested were stiff, having a Young's modulus of at least $425 \mathrm{MPa}$. While sample elongation on the SER is in one dimension, the strain is not truly uniaxial, because the sample is forced to bend around the SER drum. This makes comparison of SER measurements with traditional tensile tests difficult, particularly for stiff samples where bending may contribute to failure. The stiff nature of the AEM films caused some samples to fail at the attachment pins, however the measured properties (stress, elongation, and modulus) were statistically the same as samples that failed in the middle so all tests were included when calculating average properties and the associated error. All reported properties are the averages of at least five replicate experiments at each temperature and humidity condition, error bars represent one standard deviation.

The mechanical behavior of all three membranes at $30^{\circ} \mathrm{C}$ and dry conditions are compared in Figure 4. The ATMPP membrane is the stiffest film, represented by the steepest initial slope in the stress strain curve, due to the rigid nature of the branched polyphenylene backbone. The ATMPP film also has a higher yield point, with the yield strain around $15 \%$ and yield stress around $65 \mathrm{MPa}$. The FAA-PEEK and ETFE-g-PVBTMA films both have a lower yield point, around $10 \%$ strain and $35 \mathrm{MPa}$. Due to its stiffer nature and higher yield point, the ATMPP film withstands the highest stress at failure $(75 \mathrm{MPa})$. The FAA-PEEK and ETFE-g-PVBTMA withstood lower stresses, $60 \mathrm{MPa}$ and $47 \mathrm{MPa}$ respectively. Film elongation at dry conditions was low, between 22 and $29 \%$. The modulus and strength of the AEMs at $30^{\circ} \mathrm{C}$ and dry are reasonable, however film elongation is a concern as the membranes need to withstand swelling and contraction with humidity cycling in a fuel cell.

Increasing the testing temperature from $30^{\circ} \mathrm{C}$ to $60^{\circ} \mathrm{C}$ is expected to reduce the elastic modulus and stress at break, and increase the elongation of the polymer. However, the thermal responses of the

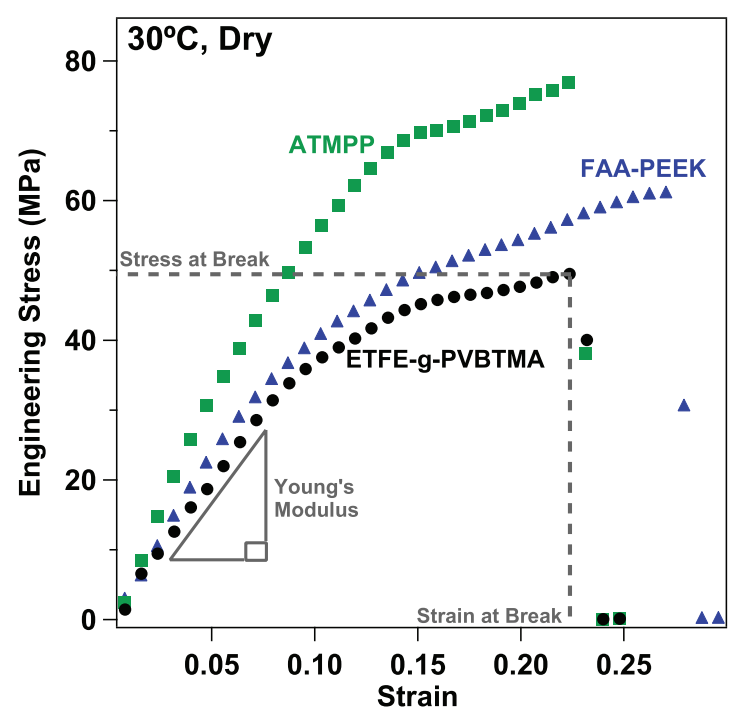

Figure 4. Representative stress vs. strain curves of the AEMs at $30^{\circ} \mathrm{C}$ under dry conditions. The linear region used to determine Young's Modulus and the defined stress and strain at break are labeled for the ETFE-g-PVBTMA film. 
Table I. Water uptake and mechanical properties from current tests and the literature (italics refer to literature data).

\begin{tabular}{|c|c|c|c|c|c|c|c|}
\hline & $\begin{array}{c}\text { Water } \\
\text { Uptake }(\%)\end{array}$ & $\begin{array}{c}\text { In-plane } \\
\text { Swelling }(\%)^{\mathrm{a}}\end{array}$ & $\begin{array}{l}\text { Conductivity } \\
(\mathrm{mS} / \mathrm{cm})\end{array}$ & $\begin{array}{c}\text { Young's } \\
\text { Modulus (MPa) }\end{array}$ & $\begin{array}{c}\text { Ultimate } \\
\text { Strength (MPa) }\end{array}$ & $\begin{array}{c}\text { Elongation } \\
(\%)\end{array}$ & Reference \\
\hline \multicolumn{8}{|l|}{ FAA-PEEK } \\
\hline $30^{\circ} \mathrm{C}$, Dry & & & & $440 \pm 30$ & $60 \pm 5$ & $29 \pm 2$ & \\
\hline $30^{\circ} \mathrm{C}, 95 \% \mathrm{RH}$ & $4.7 \pm 0.1$ & $3.3 \pm 0.1$ & & $440 \pm 30$ & $55 \pm 5$ & $41 \pm 3$ & \\
\hline $60^{\circ} \mathrm{C}, 95 \% \mathrm{RH}$ & $7.4 \pm 0.1$ & & $11.6 \pm 0.8$ & $240 \pm 20$ & $42 \pm 3$ & $44 \pm 4$ & \\
\hline PEEK & & & & 4500 & $80-120$ & $20-50$ & 36 and 37 \\
\hline $50^{\circ} \mathrm{C}, 10 \% \mathrm{RH}$ & & & & & 50 & 27 & 28 \\
\hline $60^{\circ} \mathrm{C}$, Dry & & & & $470 \pm 40$ & $73 \pm 9$ & $26 \pm 6$ & \\
\hline$\left[\mathrm{Cl}^{-}\right] \quad 60^{\circ} \mathrm{C}$, Dry & & & & $460 \pm 50$ & $60 \pm 6$ & $25 \pm 5$ & \\
\hline $30^{\circ} \mathrm{C}, 95 \% \mathrm{RH}$ & $13.9 \pm 0.3$ & $26 \pm 1$ & & $250 \pm 40$ & $25 \pm 3$ & $46 \pm 13$ & \\
\hline $50^{\circ} \mathrm{C}, 90 \% \mathrm{RH}$ & $70 \pm 6^{\mathrm{b}}$ & & $37 \pm 5^{\mathrm{b}}$ & & 20 & 80 & 28 \\
\hline $60^{\circ} \mathrm{C}, 95 \% \mathrm{RH}$ & $13.7 \pm 0.3$ & & $20 \pm 2$ & $230 \pm 20$ & $22 \pm 2$ & $56 \pm 6$ & \\
\hline $60^{\circ} \mathrm{C}$, Dry & & & & $310 \pm 60$ & $27 \pm 4$ & $10 \pm 3$ & \\
\hline $30^{\circ} \mathrm{C}, 95 \% \mathrm{RH}$ & $6.2 \pm 0.1$ & $27 \pm 2$ & & $140 \pm 40$ & $32 \pm 3$ & $130 \pm 10$ & \\
\hline$R T$, hydrated & $40 \pm 4^{\mathrm{c}}$ & & $21.7 \pm 0.8^{\mathrm{c}}$ & & $14-19$ & $45-75$ & 30 \\
\hline $60^{\circ} \mathrm{C}, 95 \% \mathrm{RH}$ & $10.4 \pm 0.1$ & & $47 \pm 3$ & $80 \pm 10$ & $22 \pm 2$ & $210 \pm 30$ & \\
\hline ETFE film & & & & $520-570$ & $150-200$ & $350-550$ & 40 \\
\hline \multicolumn{8}{|l|}{ Nafion N115 } \\
\hline $23^{\circ} \mathrm{C}, 50 \% R H$ & & & & 249 & 43 & 225 & 41 \\
\hline $23^{\circ} \mathrm{C}$, water soaked & & & & 114 & 34 & 200 & 41 \\
\hline
\end{tabular}

benchmark AEMs tested resulted in a range of responses. Exposing the AEMS to humidity allows the polymer to uptake water, which has a plasticizing effect. ${ }^{25,28,35}$ The water plasticizer generally reduces the elastic modulus, increases elongation, and decreases the stress to break. The change in mechanical properties due to humidity is dependent on the amount of water taken up by the polymer. Table I summarizes the water uptake and mechanical properties measured for each membrane at the different sample conditions and compares available literature data at similar conditions.

The FAA-PEEK film has a narrow range of mechanical changes over the range of conditions tested (Figure 5). The PEEK reinforcement increases membrane strength and durability because PEEK has a very high modulus ( $4500 \mathrm{MPa})$ and tensile strength $(\sim 100 \mathrm{MPa}) .^{36,37}$ The Young's moduli, represented by the initial slope of the stress vs. strain curves, are similar at $30^{\circ} \mathrm{C}$ (dry and hydrated) and $60^{\circ} \mathrm{C} / \mathrm{dry}$, being between 400 and $440 \mathrm{MPa}$. The decrease in slope at $60^{\circ} \mathrm{C}$ and saturated conditions corresponds to a lower modulus, $250 \mathrm{MPa}$, indicating a softening of the film due to the plasticizing effect of water. Elongation increases with temperature and humidity as expected, but has a relatively narrow range, from $29 \%$ to $44 \%$. Similarly, increases in temperature and humidity correspond to decreases in stress at break, from $60 \mathrm{MPa}$ at $30^{\circ} \mathrm{C}$ and dry to $42 \mathrm{MPa}$ at $60^{\circ} \mathrm{C}$ and $95 \% \mathrm{RH}$. The relatively narrow range of mechanical properties with respect to temperature and humidity is due to the PEEK reinforcement of the FAA-PEEK film that resists swelling and has no thermal transitions in this range. ${ }^{38}$

The ATMPP film has a small response to temperature between $30^{\circ} \mathrm{C}$ and $60^{\circ} \mathrm{C}$, but a large response to humidity (Figure 6). Compared to the ATMPP, a non-ionic, branched polyphenylene film was reported to have a much higher modulus (1900 MPa), similar strength (70 MPa) and lower elongation (6\%) (Table I), however these differences could be due in part to variations in molecular weight and slightly differing chemistries. ${ }^{39}$ At dry conditions, increasing temperature from $30^{\circ} \mathrm{C}$ to $60^{\circ} \mathrm{C}$ results in a $19 \%$ decrease in modulus, from $580 \mathrm{MPa}$ to $470 \mathrm{MPa}$, and negligible changes in stress at break (73-75 MPa) and elongation (23-26\%). The relatively large water uptake, $14 \%$, by the ATMPP film results in dramatically different behavior at saturated conditions. At saturated conditions the material is softened, reducing

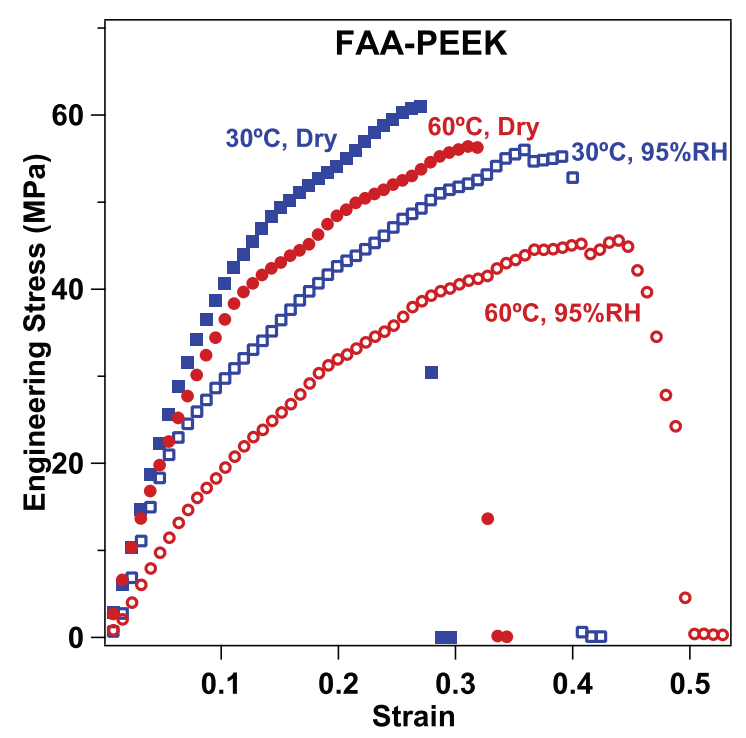

Figure 5. FAA-PEEK representative stress vs. strain curves at range of temperature and humidity conditions. 


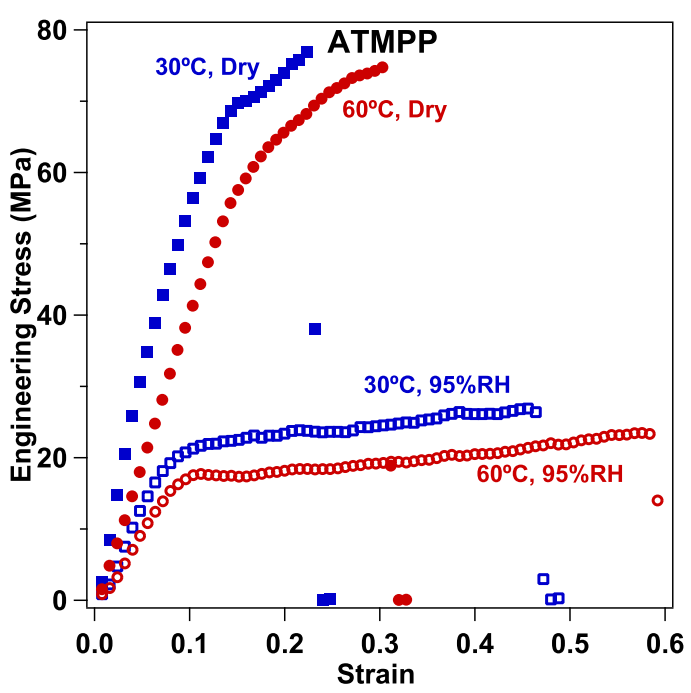

Figure 6. ATMPP representative stress vs. strain curves at range of temperature and humidity conditions.

the modulus to $250 \mathrm{MPa}$ at $30^{\circ} \mathrm{C}$ and $230 \mathrm{MPa}$ at $60^{\circ} \mathrm{C}$. At saturated conditions film strength is reduced to approximately $33 \%$ of that at dry conditions, 22-25 MPa, and elongation approximately doubled, $46-56 \%$. At saturated conditions the yield strain is relatively low, around $10 \%$, compared to the final elongation while the yield stress, around $20 \mathrm{MPa}$, is similar to the stress at break. The ATMPP was also tested at $60^{\circ} \mathrm{C}$ in the $\mathrm{Cl}^{-}$form with negligible changes in the measured properties. The dramatic reduction in modulus and strength at high hydration demonstrates the importance of testing AEM mechanical properties under operating conditions encountered in fuel cells and electrolyzers.

The ETFE-g-PVBTMA film responds dramatically to both temperature and humidity changes, Figure 7 . Radiation grafting cations results in a reduction of all mechanical properties compared to the ETFE precursor film that has high modulus (520-570 MPa), strength (150-200 MPa), and elongation (350-550\%). ${ }^{40}$ Increasing the temperature from $30^{\circ} \mathrm{C}$ to $60^{\circ} \mathrm{C}$ softened the film and resulted in lower stress at break and elongation. The modulus was reduced from $370 \mathrm{MPa}$ at $30^{\circ} \mathrm{C}$ to $310 \mathrm{MPa}$ at $60^{\circ} \mathrm{C}$. Increasing temperature also lowered stress at break to $27 \mathrm{MPa}$ compared to $47 \mathrm{MPa}$ at $30^{\circ} \mathrm{C}$, and the final elongation decreased to $10 \%$ from $22 \%$ at $30^{\circ} \mathrm{C}$. The reduction

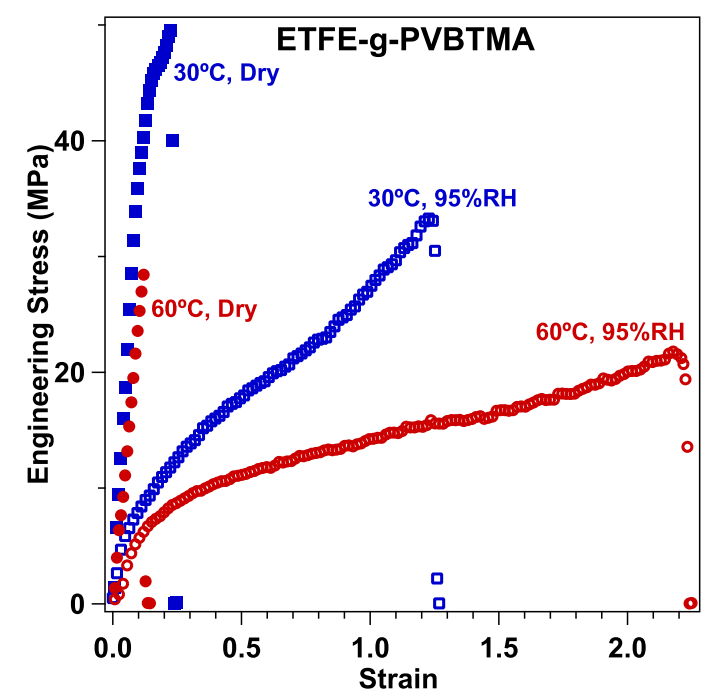

Figure 7. ETFE-g-PVBTMA representative stress vs. strain curves at range of temperature and humidity conditions. in strength with increased temperature is expected, but the reduction in elongation is counterintuitive, and may be due to a disproportionate decrease in strength compared to modulus, resulting in earlier film failure. Adding water to the polymer under saturated conditions further softens the ETFE-g-PVBTMA film. At saturated conditions the modulus was reduced between $62 \%$ to $74 \%$, to $140 \mathrm{MPa}$ at $30^{\circ} \mathrm{C}$ and $80 \mathrm{MPa}$ at $60^{\circ} \mathrm{C}$. Humidified conditions also reduced the stress at break to $32 \mathrm{MPa}$ and $22 \mathrm{MPa}$ at $30^{\circ} \mathrm{C}$ and $60^{\circ} \mathrm{C}$ respectively. Elongation is increased significantly when the ETFE-g-PVBTMA film is humidified. Elongation increases to $130 \%$ at $30^{\circ} \mathrm{C}$ and $210 \%$ at $60^{\circ} \mathrm{C}$. Due to its low elongation at dry conditions, the ETFE-g-PVBTMA film may not be able to withstand the stresses associated with dimensional shrinking when the film undergoes drying. The drastic changes in the mechanical properties of the ETFE-g-PVBTMA under different temperature and humidity conditions could contribute to membrane failure. ${ }^{15}$

The mechanical properties of the three AEMs are compared in Figure 8. All films are relatively stiff at dry conditions, i.e., having
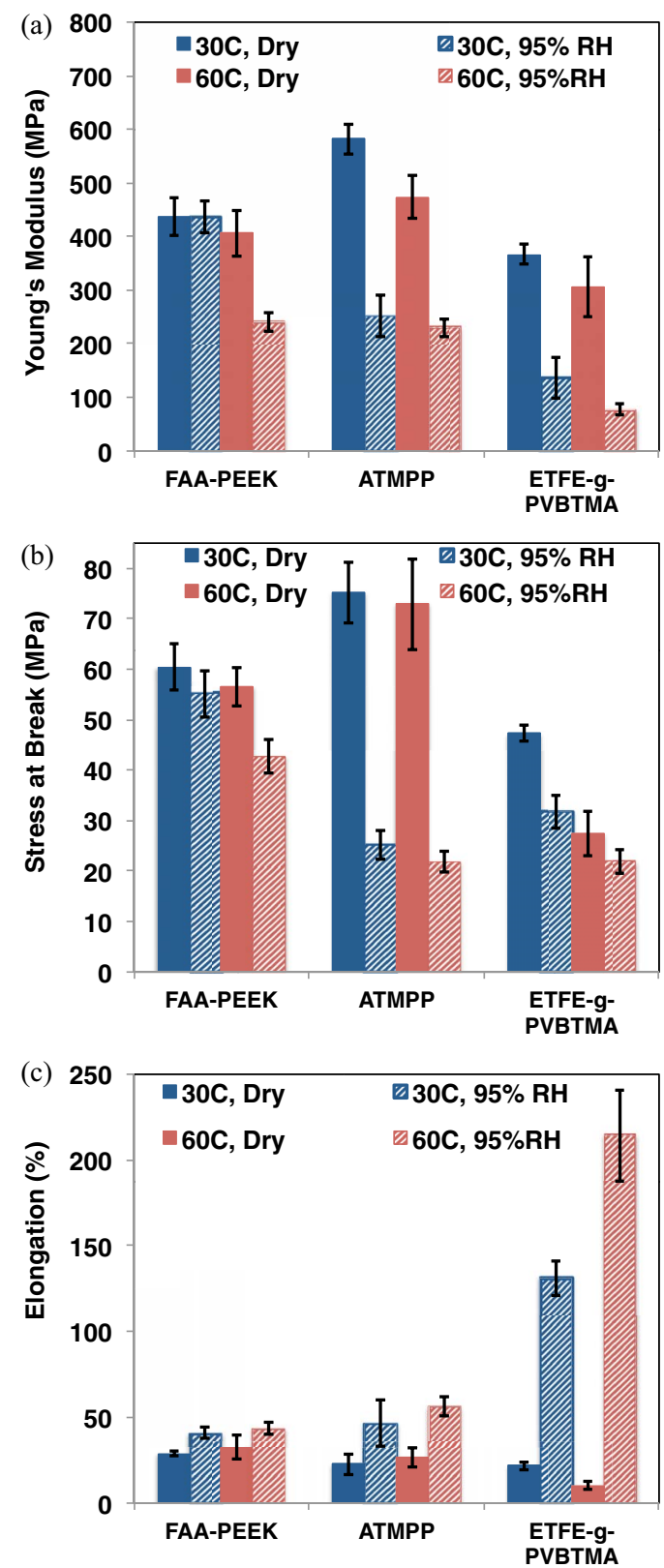

Figure 8. a) Young's modulus, b) Stress at Break, and c) Elongation of the three AEMs at $30^{\circ} \mathrm{C}$ and $60^{\circ} \mathrm{C}$ under dry and saturated conditions. 
moduli between 310 and $580 \mathrm{MPa}$. The ATMPP film is the stiffest at dry conditions but undergoes softening under hydrated conditions. The FAA-PEEK is only softened at high temperature and humidity due to low water uptake at lower temperatures. The ETFE-g-PVBTMA membrane is softened by increases in temperature and humidity, and is consistently the most elastic film at all conditions tested. The highest stress at break is seen in the ATMPP film at dry conditions, however the ATMPP film significantly decreases in strength when humidified. The FAA-PEEK has the most consistent strength at all conditions tested, most likely due to PEEK reinforcement that is not effected by changes in humidity. All films had an increase in elongation under saturated conditions. The increase in elongation was least for the FAA-PEEK due to its lower water uptake and the reinforcing mesh. The highest elongations, $130 \%$ to $210 \%$, were seen in the ETFE-g-PVBTMA film at saturated conditions, but the low elongations of the film at dry conditions could be problematic during humidity cycling. Ideally, a membrane would have high strength under both dry and humidified conditions and sufficient elongation to account for dimensional changes with hydration level. Membrane reinforcement helps resist membrane changes with temperature and humidity, as shown with the FAA-PEEK film, however adding nonconductive reinforcement also lowers polymer IEC and limits water uptake that may be critical for efficient ion transport. The interplay between ionic conductivity, water uptake, and mechanical integrity makes designing an optimal anion exchange membrane extremely challenging, but considering all of these criteria in the early stages of development will lead to a robust, well performing anion exchange membrane.

\section{Conclusions}

Testing the mechanical performance of common AEMs provided baseline properties for membrane development for electrochemical energy conversion devices and highlights what properties need improvement. The mechanical properties of three common AEMs were investigated at a range of relevant temperature and humidity conditions. The three membranes tested had different chemical and physical properties, so mechanical responses to temperature and humidity varied greatly. The Fumasep FAA-PEEK film is reinforced by a PEEK mesh that restricts water uptake, which means that hydration has a negligible affect on Young's modulus at $30^{\circ} \mathrm{C}$ and produces only a $40 \%$ reduction at $60^{\circ} \mathrm{C}$. Similarly, the hydrated strength decreases by only $9 \%$ and $24 \%$ at $30^{\circ} \mathrm{C}$ and $60^{\circ} \mathrm{C}$ respectively. The ATMPP film had the highest IEC, resulting in large water uptake and significant softening, a $51-55 \%$ reduction in modulus, and a $70 \%$ weakening of the film at saturated conditions. The ETFE-gPVBTMA film responded to both temperature and humidity, having the largest increase in elongation at saturated conditions, over $200 \%$ when hydrated at $60^{\circ} \mathrm{C}$. The ETFE-g-PVBTMA film may have difficulty maintaining membrane integrity during humidity cycling because the dimensional swelling exceeds the elongation at dry conditions. Ionic groups of the AEM facilitate water uptake, which is critical to ion transport through the membrane, however water sorption leads to dimensional swelling and variation of mechanical properties. An AEM must be mechanically stable at a range of hydration levels to operate in a fuel cell, electrolyzer, or other electrochemical energy conversion device. Thus, mechanical durability, along with ionic conductivity and chemical stability, should be a fundamental design criterion for new AEM development to achieve robust device membranes.

\section{Acknowledgments}

The authors thank the Army Research Office for support of this research under the MURI \#W911NF-10-1-0520 and DURIP \#W911NF11-1-0306 and the NSF Polymer REU under EEC-1156745. The membrane synthesis at the University of Surrey was supported by EPSRC grant EP/I004882/1. Sandia National Laboratories is a multiprogram laboratory operated by Sandia Corporation, a wholly owned subsidiary of Lockheed Martin Company, for the U. S. Department of Energy's National Nuclear Security Administration under contract DE-AC04-94AL85000.

\section{References}

1. B. C. Steele and A. Heinzel, Nature, 414, 345 (2001)

2. B. Smitha, S. Sridhar, and A. A. Khan, J Membrane Sci, 259, 10 (2005).

3. R. Borup, et al., Chem. Rev., 107, 3904 (2007).

4. S. Subianto, et al., Journal of Power Sources, 233, 216 (2013).

5. M. A. Hickner, H. Ghassemi, Y. S. Kim, B. R. Einsla, and J. E. McGrath, Chem. Rev., 104, 4587 (2004).

6. M. P. Rodgers, L. J. Bonville, H. R. Kunz, D. K. Slattery, and J. M. Fenton, Chem Rev., 112, 6075 (2012)

7. G. F. McLean, T. Niet, S. Prince-Richard, and N. Djilali, International Journal of Hydrogen Energy, 27, 507 (2002).

8. J. R. Varcoe and R. C. T. Slade, Fuel Cells, 5, 187 (2005)

9. G. Couture, A. Alaaeddine, F. Boschet, and B. Ameduri, Progress in Polymer Science, 36, 1521 (2011)

10. G. R. Merle, M. Wessling, and K. Nijmeijer, J Membrane Sci, 377, 1 (2011).

11. M. A. Hickner, A. M. Herring, E. B. Coughlin, M. A. Hickner, E. B. Coughlin, A. M. Herring, and A. M. Editors. J Polym Sci Pol Phys, 51, 1727 (2013).

12. S. Chempath, J. M. Boncella, L. R. Pratt, N. Henson, and B. S. Pivovar, J. Phys. Chem. C, 114, 11977 (2010)

13. W. M. Hayes, CRC Handbook of Chemistry and Physics, 92th Edition W. M. Hayes, Editor, 92nd ed., CRC Press, Inc., (2011).

14. T. T. Aindow and J. O'Neill, Journal of Power Sources, 196, 3851 (2011).

15. M. Pestrak, et al., J. Fuel Cell Sci. Technol., 7, 041009 (2010).

16. W. Schmittinger and A. Vahidi, Journal of Power Sources, 180, 1 (2008).

17. Y. P. Patil, W. L. Jarrett, and K. A. Mauritz, J Membrane Sci, 356, 7 (2010).

18. X. Huang, et al., J Polym Sci Pol Phys, 44, 2346 (2006).

19. Y.-H. Lai, C. K. Mittelsteadt, C. S. Gittleman, and D. A. Dillard, J. Fuel Cell Sci. Technol., 6, 021002 (2009)

20. D. A. Dillard, et al., J. Fuel Cell Sci. Technol., 6, 031014 (2009).

21. A. M. Herring, et al., ECS Transactions, 3, 915 (2006).

22. N. J. Robertson, et al., J. Am. Chem. Soc., 132, 3400 (2010).

23. G. A. Giffin, S. Lavina, G. Pace, and V. Di Noto, J. Phys. Chem. C, 116, 23965 (2012).

24. H. Tang, S. Peikang, S. P. Jiang, F. Wang, and M. Pan, Journal of Power Sources, 170, 85 (2007).

25. M. B. Satterfield and J. B. Benziger, J Polym Sci Pol Phys, 47, 11 (2009).

26. J. B. Fumatech, Technical Datasheet - fumasep FAA-PK, p. 2, Fumatech, (2012), p. $1-2$.

27. M. R. Hibbs, C. H. Fujimoto, and C. J. Cornelius, Macromolecules, 42, 8316 (2009).

28. C. Fujimoto, D.-S. Kim, M. Hibbs, D. Wrobleski, and Y. S. Kim, J Membrane Sci, 423-424, 438 (2012)

29. R. Janarthanan, et al., J Polym Sci Pol Phys, 51, 1743 (2013)

30. J. R. Varcoe, et al., Chem Mater, 19, 2686 (2007)

31. O. I. Deavin, et al., Energy Environ. Sci., 5, 8584 (2012).

32. P. V. Mazin, N. A. Kapustina, and M. R. Tarasevich, Russian Journal of Electrochemistry, 47, 275 (2011).

33. G. Chikvaidze, J. Gabrusenoks, J. Kleperis, and G. Vaivars, J. Phys.: Conf. Ser., 93, 012026 (2007).

34. M. L. Sentmanat, Rheol Acta, 43, 657 (2004)

35. P. W. Majsztrik, A. B. Bocarsly, and J. B. Benziger, Macromolecules, 41, 9849 (2008).

36. M. Berer, Z. Major, G. Pinter, D. M. Constantinescu, and L. Marsavina, Mech TimeDepend Mater (2013).

37. X. Li, et al., J Membrane Sci, 254, 147 (2005).

38. S. Z. Cheng, M. Y. Cao, and B. Wunderlich, Macromolecules, 19, 1868 (1986).

39. A. L. Rusanov, D. Y. Likhachev, O. V. Kozlova, and F. W. Harris, Progress in Polymer Science, 31, 749 (2006).

40. D. S. A. De Focatiis and L. Gubler, Polymer Testing, 32, 1423 (2013).

41. L. DuPont, DuPont Nafion PFSA Membranes, p. 4, data sheet, (2009), p. 1-4. 